\title{
An observational study of bimatoprost $0.01 \%$ in treatment-naïve patients with primary open angle glaucoma or ocular hypertension: the CLEAR trial
}

This article was published in the following Dove Press journal:

Clinical Ophthalmology

17 December 2012

Number of times this article has been viewed

\author{
Donald R Nixon' \\ Susan Simonyi² \\ Meetu Bhogal ${ }^{2}$ \\ Christopher S Sigouin ${ }^{3}$ \\ Andrew C Crichton ${ }^{4}$ \\ Marino Discepola ${ }^{5}$ \\ Cindy ML Hutnik ${ }^{6}$ \\ David B Yan ${ }^{7}$ \\ 'Private Practice, Barrie, ON, \\ ${ }^{2}$ Allergan Inc, Markham, ON, \\ ${ }^{3}$ CLINWest Research, Burlington, \\ $\mathrm{ON},{ }^{4}$ University of Calgary, Calgary, \\ $A B,{ }^{5}$ McGill University, Montreal, QC, \\ ${ }^{6}$ London Health Sciences Centre, \\ London, ON, ${ }^{7}$ University of Toronto, \\ Toronto, ON, Canada
}

Background: This study was designed to evaluate the occurrence and severity of ocular hyperemia in subjects with elevated intraocular pressure (IOP) due to primary open angle glaucoma (POAG) or ocular hypertension (OHT) following treatment with bimatoprost $0.01 \%$ in a real-world clinical setting.

Methods: This was an open-label, observational study conducted at 67 centers in Canada. Subjects with elevated IOP due to POAG or OHT instilled bimatoprost $0.01 \%$ topically as monotherapy once daily. Ocular hyperemia was graded by the investigator at baseline and weeks 6 and 12 using a photographic five-point grading scale. Change in IOP from baseline was also evaluated at these time points. This analysis includes only the subgroup of 522 subjects who were naïve to IOP-lowering medication prior to the study.

Results: After 12 weeks of treatment with bimatoprost $0.01 \%$, hyperemia was graded as noneto-mild (grades $0,+0.5$, or +1 ) for $93.3 \%$ of subjects and as moderate-to-severe (grades +2 or +3 ) for $6.7 \%$. At weeks 6 and 12, most subjects (93.2\% and 93.5\%) had no change in hyperemia grade from baseline. IOP was reduced by $7.4 \mathrm{mmHg}(29.8 \%)$ at week 6 and $7.7 \mathrm{mmHg}(30.9 \%)$ at week 12 from baseline.

Conclusion: This real-world, observational study found that bimatoprost $0.01 \%$ instilled once daily reduced IOP by a mean of $30 \%$ from baseline without moderate or severe ocular hyperemia in $93 \%$ of treatment-naïve subjects with POAG or OHT.

Keywords: glaucoma, intraocular pressure, hyperemia, bimatoprost

\section{Introduction}

For patients with glaucoma or ocular hypertension (OHT), decreasing intraocular pressure (IOP) is critical in preventing disease progression and forestalling visual loss. Bimatoprost is a prostamide that effectively lowers IOP. Bimatoprost has been found to be safe and effective as monotherapy and superior to timolol maleate in reducing IOP. ${ }^{1}$ Other studies have found that IOP-lowering with bimatoprost $0.03 \%$ is equal or superior to that achieved with travoprost or latanoprost $\mathrm{t}^{2-5}$ and that bimatoprost further reduces IOP in patients who switched from latanoprost. ${ }^{6,7}$

Despite the efficacy of bimatoprost $0.03 \%$, its full adoption has been limited by the local side effect of hyperemia. Conjunctival hyperemia or "red eye" is a nonspecific clinical term that implies vasodilatation of the conjunctival blood vessels. Moreover, aside from cosmetic concern, there are no other proven consequences associated with conjunctival hyperemia secondary to treatment with prostaglandins or prostamides. Patient tolerance of a prescribed topical ocular IOP-lowering medication is critical in order to maintain good IOP control, and hyperemia is the most frequently reported
Correspondence: Donald R Nixon 190 Cundles Road, Suite 100C, Barrie, Ontario L4M 4S5, Canada Tel + I 7057373737

Fax +I 7057277605

Email trimedeyedoc@gmail.com 
cause for patient intolerance of the prostaglandin analog class of glaucoma medications. ${ }^{8}$

In an attempt to enhance tolerability and improve patient compliance, bimatoprost $0.03 \%$ was reformulated to reduce the concentration of active medication to $0.01 \%$. In a Phase III clinical trial, bimatoprost $0.01 \%$ was determined to be equivalent to the original bimatoprost $0.03 \%$ formulation in IOP-lowering efficacy throughout the 12 months of the study. ${ }^{9}$ Additionally, in the same study, treatment with bimatoprost $0.01 \%$ was shown to have improved tolerability and safety over bimatoprost $0.03 \% .{ }^{9}$ However, as with all Phase III trials, questions concerning the performance of approved therapies in larger patient populations are left unanswered. As a result, Allergan Inc., the sponsoring pharmaceutical company, and members of the Canadian ophthalmic community formed a partnership to study the performance of bimatoprost $0.01 \%$ in the setting of actual clinical practice through The Canadian Lumigan RC Early Analysis Review (CLEAR) study. Here we report the results of this observational study in the group of subjects previously naïve to IOP-lowering therapy.

\section{Materials and methods Study design and subjects}

This was a 12-week, open-label, noncomparative clinical evaluation of patients with primary open angle glaucoma (POAG) or OHT who were treated with bimatoprost $0.01 \%$ (Lumigan ${ }^{\circledR}$ RC, Allergan Inc.) monotherapy at 67 centers in Canada. The study was conducted between December 2, 2009 and March 23, 2011.

Subjects were eligible for inclusion if they were at least 18 years of age and had a diagnosis of elevated IOP due to either POAG or OHT and had already been determined by the treating physician to be a candidate for bimatoprost $0.01 \%$ therapy. Subjects were excluded if they reported any hypersensitivity to benzalkonium chloride, any prostaglandin analog, or any component of the study medication, or had any other abnormal ocular condition or symptom that would have prevented the subject from entering the trial. Women who were pregnant, nursing, planning a pregnancy, or of childbearing potential and not using a reliable form of contraception were also excluded. The overall study included both subjects who were naïve to any IOP-lowering medications as well as those whose target IOP was not reached with their current therapy. However, the analysis presented here only includes subjects who were naïve to IOP-lowering medications prior to the study and were treated with bimatoprost $0.01 \%$ monotherapy. Data from subjects who were previously treated with medication are described in a separate paper.

The study was conducted in accordance with the Declaration of Helsinki and the guidelines set forth by the International Council on Harmonization of Technical Requirements for Registration of Pharmaceuticals for Human Use and the United States Code of Federal Regulations CFR21. All investigators obtained appropriate institutional review board or ethics committee approval before initiating the study, and all patients provided written informed consent before any study-related procedures or changes in treatment.

\section{Treatment}

Bimatoprost $0.01 \%$ was obtained by the patient through commercial means and not as investigational study drug provided by Allergan Inc. At the baseline visit, subjects were provided with bimatoprost $0.01 \%$ and were instructed to self-instill their medication into the affected eye(s) in the evening at approximately $8 \mathrm{pm}$. Other therapy considered necessary for the patient's welfare was given at the discretion of the treating physician and was documented.

\section{Outcome variables}

Outcome variables were evaluated at baseline and at weeks 6 and 12 at 10 am ( \pm 2 hours). The primary outcome variable was the occurrence and severity of ocular hyperemia at week 12, using a photographic five-point grading scale: 0 , none, normal; +0.5 trace, trace flush reddish pink; +1 , mild, mild flush reddish color; +2 , moderate, bright red color; +3 , severe, deep, bright, diffuse redness. ${ }^{9}$

The efficacy endpoints were IOP change and IOP percent change from baseline at weeks 6 and 12. IOP was measured using a tonometer affixed to a slit lamp with the patient seated. The examiners performed IOP measurements at approximately the same time of the day for a given patient throughout the study. Adverse events were documented throughout the study, including their seriousness, severity, action taken and relationship to treatment.

\section{Statistical analyses}

All subjects who provided informed consent and completed the screening/baseline visit were included in the analyses. Individual hyperemia scores were summarized as frequency counts and percentages for all visits, and change from baseline was reported at weeks 6 and 12. Hyperemia grading was collapsed into two categories, ie, none-to-mild (ratings of $0,+0.5$, or +1 ) and moderate-to-severe (ratings 
of +2 or +3 ). These data were summarized as frequency counts and percentages at all visits. The change in hyperemia grading responses from baseline at weeks 6 and 12 for the collapsed grading categories was summarized as improved, no change, or worsened. A change in hyperemia was defined for statistical analysis as a shift from one hyperemia grouping to another from baseline to week 6 or week 12 during the study. A two-sided McNemar test was used to test for treatment effect.

For IOP, data from the eye with the higher IOP at baseline (worse eye) were used or the right eye was used if both eyes had the same IOP at baseline. IOP was summarized at each visit using descriptive statistics. IOP change and IOP percent change from baseline were analyzed at weeks 6 and 12 using two-sided paired $t$-tests.

The study was exploratory in nature and thus no formal sample size calculations were carried out. The SAS ${ }^{\circledR}$ System for Windows (SAS, Cary, NC) version 9.2 was used for the analyses. All statistical tests were performed as two-sided tests with the significance level set at $P \leq 0.05$. $P$ values were not adjusted for multiple comparisons.

\section{Results}

\section{Demographics and disposition}

A total of 1137 subjects were enrolled in the CLEAR trial at 67 Canadian centers. Of the total population of subjects, 615 subjects had been treated with a prior IOPlowering medication and were switched to bimatoprost $0.01 \%$ as adjunctive IOP-lowering therapy $(\mathrm{n}=165)$ or as monotherapy $(\mathrm{n}=450)$; the latter group is considered in a separate paper. The remaining 522 subjects were treatmentnaïve (untreated prior to baseline) and are the basis of the present analysis. Sixty-four of the 522 naïve-to-treatment subjects were discontinued for the following reasons: lost to follow-up ( $\mathrm{n}=28,5.4 \%)$, ocular adverse event $(\mathrm{n}=23$, $4.4 \%)$, other adverse event ( $n=1,0.2 \%)$, and reasons not related to adverse events $(\mathrm{n}=12,2.3 \%)$. Of the 23 naïveto-treatment subjects who discontinued the study due to ocular adverse events, 20 subjects had reported a total of 31 ocular adverse events that were related to bimatoprost $0.01 \%$ monotherapy (Table 1 ). Additionally, one subject had reported two ocular adverse events unrelated to bimatoprost $0.01 \%$ monotherapy. Three subjects did not report an adverse event.

Of the 522 naïve-to-treatment subjects enrolled to receive bimatoprost $0.01 \%$ monotherapy, 276 (52.9\%) were female, with a mean age of 66.3 years. The mean age for the 246 (47.1\%) male subjects was 63.9 years. Common associated
Table I Early discontinuation due to treatment-related ocular adverse events

\begin{tabular}{lll}
\hline Adverse event & $\begin{array}{l}\text { Subjects } \\
\mathbf{n}(\%)\end{array}$ & $\begin{array}{l}\text { Events } \\
\text { (n) }\end{array}$ \\
\hline Ocular hyperemia & $9(\mathrm{I} .7)$ & 9 \\
Eye irritation & $3(0.8)$ & 4 \\
Eye pruritus & $4(0.8)$ & 4 \\
Conjunctival hyperemia & $2(0.4)$ & 2 \\
Hyperemia & $2(0.4)$ & 2 \\
Conjunctival irritation & $\mathrm{I}(0.2)$ & $\mathrm{I}$ \\
Dermatitis & $\mathrm{I}(0.2)$ & $\mathrm{I}$ \\
Drug intolerance & $\mathrm{I}(0.2)$ & $\mathrm{I}$ \\
Dry eye & $\mathrm{I}(0.2)$ & $\mathrm{I}$ \\
Eye pain & $\mathrm{I}(0.2)$ & $\mathrm{I}$ \\
Foreign body sensation in eyes & $\mathrm{I}(0.2)$ & $\mathrm{I}$ \\
Headache & $\mathrm{I}(0.2)$ & $\mathrm{I}$ \\
Lacrimation increased & $\mathrm{I}(0.2)$ & $\mathrm{I}$ \\
Pruritus & $\mathrm{I}(0.2)$ & $\mathrm{I}$ \\
Vision blurred & $\mathrm{I}(0.2)$ & $\mathrm{I}$ \\
\hline
\end{tabular}

medical comorbidities among the enrolled 522 naïve-totreatment subjects included hypertension $(n=231,44.3 \%)$, cardiovascular disease $(\mathrm{n}=106,20.3 \%)$, diabetes $(\mathrm{n}=77$, $14.8 \%)$, asthma ( $\mathrm{n}=44,8.4 \%)$, and pulmonary disease $(\mathrm{n}=27,5.2 \%)$. Some of the enrolled naïve-to-treatment subjects had more than one comorbidity.

\section{Hyperemia}

Table 2 shows the occurrence and severity of ocular hyperemia associated with the once daily use of bimatoprost $0.01 \%$ in subjects who were naïve to treatment, based on the five-point hyperemia grading scale.

Table 3 shows the rates of ocular hyperemia grading collapsed into none-to-mild $(0,+0.5,+1)$ and moderateto-severe $(+2,+3)$ groupings. At baseline, $1.5 \%$ of naïveto-treatment subjects presented with moderate-to-severe hyperemia $(+2,+3)$. At the 12 -week primary endpoint of the study, $6.7 \%$ of subjects were in the moderate-to-severe hyperemia grouping, whereas $93.3 \%$ of subjects were in the none-to-mild hyperemia grouping $(0,+0.5$, or +1$)$. Results showed an increase in the percentage of subjects in the moderate-to-severe hyperemia grouping at week 6 and

Table 2 Rates of occurrence and severity of ocular hyperemia

\begin{tabular}{llll}
\hline $\begin{array}{l}\text { Hyperemia } \\
\text { grade }\end{array}$ & $\begin{array}{l}\text { Baseline } \\
(\mathbf{n}=\mathbf{5 2 2})\end{array}$ & $\begin{array}{l}\text { Week 6 } \\
(\mathbf{n}=\mathbf{4 9 7})\end{array}$ & $\begin{array}{l}\text { Week I2 } \\
(\mathbf{n}=\mathbf{4 6 0})\end{array}$ \\
\hline 0 & $306(58.6 \%)$ & $153(30.8 \%)$ & $148(32.2 \%)$ \\
+0.5 & $152(29.1 \%)$ & $208(41.9 \%)$ & $183(39.8 \%)$ \\
$+\mathrm{I}$ & $56(10.7 \%)$ & $98(19.7 \%)$ & $98(21.3 \%)$ \\
+2 & $8(1.5 \%)$ & $33(6.6 \%)$ & $27(5.9 \%)$ \\
+3 & 0 & $5(1.0 \%)$ & $4(0.9 \%)$ \\
\hline
\end{tabular}


Table 3 Hyperemia grouping frequency (\%) of naïve-to-treatment subjects receiving bimatoprost $0.01 \%$ monotherapy

\begin{tabular}{llll}
\hline Hyperemia grouping & Baseline & Week 6 & Week I2 \\
\hline $\begin{array}{l}\text { None-to-mild } \\
(0,+0.5,+1)\end{array}$ & $514(98.5 \%)$ & $459(92.4 \%)$ & $429(93.3 \%)$ \\
$\begin{array}{l}\text { Moderate-to-severe } \\
(+2,+3)\end{array}$ & $8(1.5 \%)$ & $38(7.6 \%)$ & $31(6.7 \%)$ \\
\hline
\end{tabular}

week 12 compared with baseline rates of ocular hyperemia. There was no minimal change in moderate-to-severe hyperemia between weeks 6 and 12 on treatment with bimatoprost $0.01 \%$ monotherapy during the trial.

Figure 1 illustrates the change in hyperemia from baseline during the study using a McNemar analysis of shift from none-to-mild to moderate-to-severe hyperemia groupings (worsening) or vice-versa (improving) or no change. A very small percentage of subjects improved in hyperemia grading (ie, from moderate-to-severe to none-to-mild) at the week 6 or 12 visits. A small percentage of the naïve-to-treatment population worsened in hyperemia grading (ie, none-to-mild to moderate-to-severe) at the week 6 and week 12 visits. The majority of subjects did not experience a shift in hyperemia grading at weeks 6 or 12. The statistical analysis of the change in hyperemia grading from baseline showed a statistically significant $(P<0.05)$ worsening of hyperemia at both the week 6 and week 12 visits.

\section{Intraocular pressure}

Mean ( \pm standard deviation) IOP at baseline was $23.5 \pm 5.8 \mathrm{mmHg}$. Following initiation of bimatoprost $0.1 \%$ monotherapy at weeks 6 and 12 , mean \pm SD IOP was $16.2 \pm 3.9 \mathrm{mmHg}$ and $15.9 \pm 3.9 \mathrm{mmHg}$, respectively.

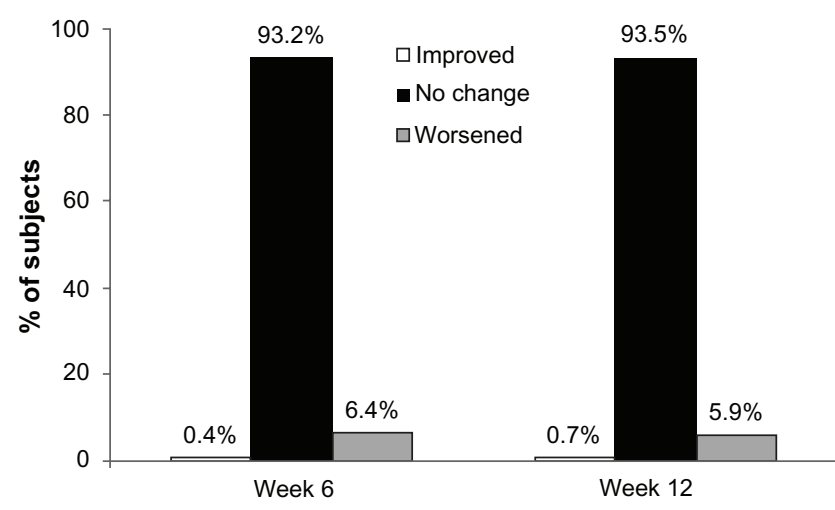

Figure I Change in ocular hyperemia groupings from baseline (ie, shift from moderate-to-severe hyperemia to none-to-mild hyperemia or improved, no change, and none-to-mild hyperemia to moderate-to-severe ocular hyperemia or worsened). Note: The changes in collapsed hyperemia grading categories from baseline to weeks 6 and 12 were both statistically significant $(P<0.05)$.
This reduction in IOP corresponds to a mean $\pm \mathrm{SD}$ percent change from baseline of $-29.8 \% \pm 15.5 \%$ at week 6 and $-30.9 \% \pm 15.4 \%$ at week 12 , which was statistically significant (both $P<0.05$; Figure $2 \mathrm{~A}$ ). The absolute mean level of IOP changed by $-7.4 \mathrm{mmHg}$ and $-7.7 \mathrm{mmHg}$ at 6 and 12 weeks, respectively (both $P<0.05$; Figure 2B).

\section{Safety}

In this study population, 35 subjects reported 57 adverse events, for an overall incidence of $6.7 \%(35 / 522)$. A total of 48 adverse events, reported by 29 subjects, were considered related to treatment, for an incidence of 5.6\% (29/522; Table 4). One serious adverse event (death) occurred in this study population and was considered unrelated to treatment. The most frequently reported treatment-related adverse events were ocular hyperemia $(2.1 \%, 11 / 522)$, eye irritation $(0.8 \%$, $4 / 522)$, eye pruritus $(0.8 \%, 4 / 522)$, conjunctival hyperemia $(0.6 \%, 3 / 522)$, and hypertrichosis $(0.6 \%, 3 / 522)$.
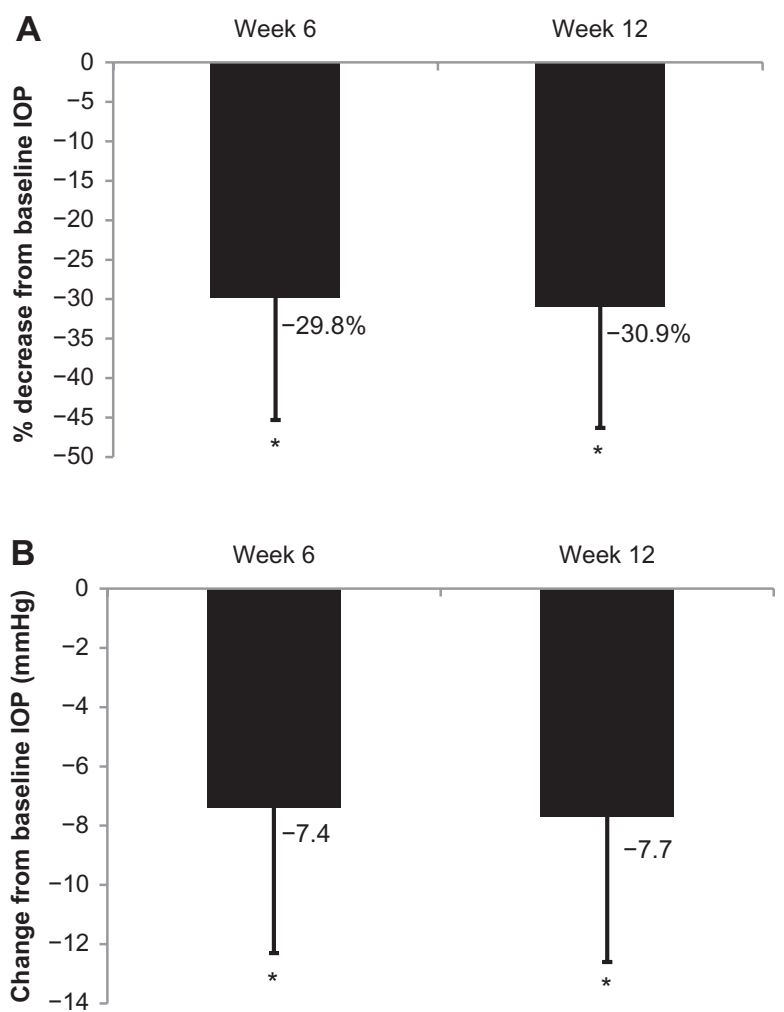

Figure 2 Change from baseline IOP. (A) Percentage change from baseline following initiation of bimatoprost $0.01 \%$ monotherapy in naive to IOP-lowering treatment subjects at weeks 6 and 12, error bars indicate standard deviation. (B) Absolute change from baseline following initiation of bimatoprost $0.01 \%$ monotherapy in naïve to IOP-lowering treatment subjects at weeks 6 and I2, error bars indicate standard deviation.

Note: *Significant change from baseline, $P<0.05$. 
Table 4 Treatment-related adverse events reported by at least two subjects

\begin{tabular}{lll}
\hline Adverse event & $\begin{array}{l}\text { Subjects } \\
\mathbf{n}(\%)\end{array}$ & $\begin{array}{l}\text { Events } \\
\mathbf{n}\end{array}$ \\
\hline Ocular hyperemia & $\mathrm{II}(2.1)$ & $\mathrm{II}$ \\
Eye irritation & $4(0.8)$ & 5 \\
Eye pruritus & $4(0.8)$ & 4 \\
Conjunctival hyperemia & $3(0.6)$ & 3 \\
Hypertrichosis & $3(0.6)$ & 3 \\
Dry eye & $2(0.4)$ & 2 \\
Eye pain & $2(0.4)$ & 2 \\
Foreign body sensation in eyes & $2(0.4)$ & 2 \\
Headache & $2(0.4)$ & 2 \\
Hyperemia & $2(0.4)$ & 2 \\
Pruritus & $2(0.4)$ & 2 \\
\hline
\end{tabular}

\section{Discussion}

The objective of the CLEAR study was to evaluate the performance of bimatoprost $0.01 \%$ further in a real-world setting beyond the confines of a randomized clinical trial with its tightly defined eligibility criteria. In a larger population with much wider enrolment criteria as in the CLEAR study, the results might better reflect what one would observe in actual clinical practice.

The findings from this 3-month, open-label, noncomparative, observational study demonstrate that treatment-naïve POAG or OHT subjects who received bimatoprost $0.01 \%$ showed a $30 \%$ mean change in IOP reduction from baseline. The majority of subjects did not experience a shift in hyperemia grading at week 6 or week 12 relative to untreated baseline (ie, $93.2 \%$ and $93.5 \%$, respectively). In this naïve to treatment population, there was only a statistically significant shift to moderate or severe hyperemia in $6.4 \%$ of patients at week 6 and $5.9 \%$ of patients at week 12 . The results of this study are consistent with those obtained by Katz et al who demonstrated that bimatoprost $0.01 \%$ is not only equivalent in IOP-lowering efficacy to bimatoprost $0.03 \%$, but also provides improved tolerability with less frequent and severe conjunctival hyperemia. ${ }^{9}$ These results are also consistent with those of a European, open-label observational study of $0.01 \%$ bimatoprost, which found a $6.5 \mathrm{mmHg}$ lowering of IOP in treatment-naïve subjects, accompanied by a low rate $(2.5 \%)$ of ocular or conjunctival hyperemia. ${ }^{10}$ In contrast with the recent report by Pfennigsdorf et al, ${ }^{10}$ the data presented here enable a more detailed analysis of ocular hyperemia attributed to bimatoprost $0.01 \%$ monotherapy as first-line IOP-lowering therapy for POAG and OHT patients through inclusion of a standardized ocular hyperemia severity grading system and assessment of IOP-lowering efficacy across three study visits (ie, baseline and at weeks 6 and 12).
After 12 weeks of treatment with bimatoprost $0.01 \%$, $93.3 \%$ of subjects had a hyperemia grade up to and including grade 1, which was deemed none-to-mild, and $93.5 \%$ had no change in hyperemia grade from baseline. The levels of conjunctival hyperemia categorized as moderate-to-severe (ie, grade +2 or $+3,6.7 \%$ ) in the present study are higher than that reported by Katz et al (ie, 3.2\% showed moderate to severe increase from baseline). ${ }^{9}$ It should be noted that in addition to differences in study duration of the former versus the latter study (12 weeks versus 6 months, respectively) the subject population of this report involves analysis of subjects who were naïve to any IOP-lowering medication, whereas subjects assessed by Katz et al included subjects who received bimatoprost $0.01 \%$ following washout of any previous IOP-lowering therapy. ${ }^{9}$

Hyperemia is a common side effect among all prostaglandin analogs, but its underlying mechanism remains unclear. Ocular surface hyperemia has been postulated to be related to either pharmacological or inflammatory processes or both. However, a histological study failed to demonstrate increased inflammation reactions in conjunctival biopsies derived from patients with ocular hyperemia when compared with healthy controls. ${ }^{11}$ This was later confirmed with in vivo experiments of rabbits, dogs, and monkeys treated topically with bimatoprost, which ranged in concentration from $0.001 \%$ to $0.1 \%$ and was administered either four times, twice or once daily over one, six or 12 months, which did not show evidence of conjunctival inflammatory processes. ${ }^{12}$ Hyperemia due to prostaglandin analogs seems to be caused by a common signaling mechanism that involves nitric oxide, a known vasodilator. $^{13}$

The secondary objective in this study was to assess the change from baseline IOP at the 6-week and 12-week study visits. After 6 weeks of treatment with bimatoprost $0.01 \%$, IOP showed a mean decline of $-7.4 \mathrm{mmHg}$ and a mean percentage change of $-29.8 \%$ from baseline $(23.5 \pm 5.8 \mathrm{mmHg})$. At 12 weeks, the mean IOP decline was $-7.7 \mathrm{mmHg}$ or a $-30.9 \%$ change from baseline. These results compare favorably with the results reported by Katz et al, who found that bimatoprost $0.01 \%$ decreased IOP by $-7.4 \mathrm{mmHg}$ or $-29 \%$ from baseline at 12 months. ${ }^{9}$ These results are also similar to the 12 -month data from the Higginbotham study that showed reduction of IOP from baseline of $-7.6 \mathrm{mmHg}(-30 \%)$ with the bimatoprost $0.03 \%$ ophthalmic solution formulation. ${ }^{1}$

To date, lowering IOP is the only risk factor that has been proven to modify glaucoma progression. In order for existing medications to effectively reduce IOP, patients must comply with treatment and, therefore, balancing patient 
tolerability with efficacy is a critical goal in the development of medications for glaucoma and OHT patients. Additionally, formulations that require less frequent dosing may yield a higher degree of long-term patient compliance. ${ }^{14}$

The present study was not without limitations. Due to the open-label study design observer bias by the participating physician, a Hawthorne effect for enhanced patient adherence with the study therapy may have resulted. It should also be noted that 28 (5.4\%) and $23(4.4 \%)$ of the total naïve-to-treatment subjects enrolled in the present study were either lost to follow-up or discontinued the study due to ocular adverse events. Given that exclusion of these subjects may be related to ocular adverse events, the results reported herein may understate the occurrence and severity of hyperemia attributed to bimatoprost $0.01 \%$ monotherapy in naïve-to-treatment subjects.

In conclusion, the results of this open-label study suggest that, in routine clinical use, bimatoprost $0.01 \%$ monotherapy achieves a favorable balance by pairing effective IOP-lowering with a low rate of ocular hyperemia in treatment-naïve POAG or OHT subjects.

\section{Acknowledgments}

The authors acknowledge the writing assistance of Darryl C Baptiste, MBA, Ph.D. and the editorial assistance of Mary Ann Chapman, Ph.D. This study was supported by Allergan Inc., and is reported here on behalf of the CLEAR Study Group: Iqbal Ike K Ahmed, Mississauga, ON; Rama Behki, Gatineau, PQ; Robert Beldavs, Winnipeg, MB; Francois Bellefeuille, Trois-Rivieres, PQ; Dan Belliveau, Halifax, NS; Raj Bindlish, Oakville, ON; Fadi Calotti, Brantford, ON; Jeff Chambers, Kelowna, BC; Jason Cherry, Richmond, BC; Robert Chevrier, Gloucester, ON; Alan Coffey, Westmount, PQ; Andy Crichton, Calgary, AB; Marino Discepola, Montreal, PQ; Gordon Douglas, Calgary, AB; Stephane Dupont, Gramby, PQ; Chaim Edelstein, Montreal, PQ; Stephen Fichman, Montreal, PQ; Bryce Ford, Calgary, AB; Michel Giunta, Sherbrooke, PQ; Sheldon Goldhar, Scarborough, ON; Larry Green, Sidney, BC; Francine Guay, Lévis, PQ; Eugene Hladky, Montreal, PQ; Glen Hoar, Comox, BC; Muhammad Humayun, Dartmouth, NS; Cindy Hutnik, London, ON; Norman Hwang, Burnaby, BC; Fahim Ibrahim, Point Edward, ON; Carolyn Isbister, West Vancouver, BC; Helene Joyal, Saint-Jean-sur-Richelieu, PQ; Barry Kattleman, Montreal, PQ; Baseer Khan, Vaughan, ON; Elie Khouri, Saint-Laurent, PQ; Thomas Klein, Mississauga, ON; Alain Lachance, Saint-Georges,
PQ; Hesham Lakosha, Halifax, NS; Alain Lamoureux, Sorel, PQ; Gisele Li, Montreal, PQ; Derek Lui, Woodstock, ON; Mark Lukasik, Owen Sound, ON; Sam Markowitz, Toronto, ON; Jean Mayer, St-Charles Borrome, PQ; Mohan Merchea, London, ON; Michael Miller, Mississauga, ON; Kam Mohaseb, North Vancouver, BC; Paul Murphy, Saskatoon, SK; Rashmi Nigam, Winnipeg, MB; Don Nixon, Barrie, ON; Patrick O'Keeffe, North Battleford, SK; Manuel Perrier, Lachine, PQ; Carl Peters, Penticton, BC; Theodore Rabinovitch, Downsview, ON; Aaron Rifkind, Hamilton, ON; Suleiman Sefau, Charlottetown, PE; Rob Semeniuk, Penticton, BC; Lesya Shuba, Halifax, NS; Barry Silver, Dorval, PQ; Zakaria Tadrous, Abbotsford, BC; Eric Tam, Brampton, ON; Alexander Tan, Halifax, NS; Andrew Taylor, Niagara Falls, ON; Patricia Teal, Fort Erie, ON; David Yan, Mississauga, ON; Natasha Yepes, Kitchener, ON.

\section{Disclosure}

Publication of this article was sponsored by Allergan Inc. Susan Simonyi and Meetu Bhogal are employees of Allergan Inc. Chris Sigouin is an employee of ClinWest, which received fees for assisting with statistical analysis. Drs. Donald R Nixon, Andrew C Crichton, Marino Discepola, Cindy ML Hutnik and David B Yan declare no potential conflicts of interest in this work.

\section{References}

1. Higginbotham EJ, Schuman JS, Goldberg I, et al. One-year, randomized study comparing bimatoprost and timolol in glaucoma and ocular hypertension. Arch Ophthalmol. 2002;120:1286-1293.

2. Aptel F, Cucherat M, Denis P. Efficacy and tolerability of prostaglandin analogs: a meta-analysis of randomized controlled clinical trials. J Glaucoma. 2008;17:667-673.

3. Parrish RK, Palmberg P, Sheu WP, Group XLTS. A comparison of latanoprost, bimatoprost, and travoprost in patients with elevated intraocular pressure: a 12-week, randomized, masked-evaluator multicenter study. Am J Ophthalmol. 2003;135:688-703.

4. Kymes SM, Burk C, Feinman T, Williams JM, Hollander DA. Demonstration of an online tool to assist managed care formulary evidence-based decision making: meta-analysis of topical prostaglandin analog efficacy. Ther Clin Risk Manag. 2011;7:283-290.

5. Noecker RS, Dirks MS, Choplin NT, et al. A six-month randomized clinical trial comparing the intraocular pressure-lowering efficacy of bimatoprost and latanoprost in patients with ocular hypertension or glaucoma. Am J Ophthalmol. 2003;135:55-63.

6. Law SK, Song BJ, Fang E, Caprioli J. Feasibility and efficacy of a mass switch from latanoprost to bimatoprost in glaucoma patients in a prepaid Health Maintenance Organization. Ophthalmology. 2005;112: 2123-2130.

7. Craven ER, Liu CC, Batoosingh A, Schiffman RM, Whitcup SM. A randomized, controlled comparison of macroscopic conjunctival hyperemia in patients treated with bimatoprost $0.01 \%$ or vehicle who were previously controlled on latanoprost. Clin Ophthalmol. 2010;4: 1433-1440.

8. Hollo G. The side effects of the prostaglandin analogues. Expert Opin Drug Saf. 2007;6:45-52. 
9. Katz LJ, Cohen JS, Batoosingh AL, Felix C, Shu V, Schiffman RM. Twelve-month, randomized, controlled trial of bimatoprost $0.01 \%$, $0.0125 \%$, and $0.03 \%$ in patients with glaucoma or ocular hypertension. Am J Ophthalmol. 2010;149:661-671. e661.

10. Pfennigsdorf S, Ramez O, von Kistowski G, et al. Multicenter, prospective, open-label, observational study of bimatoprost $0.01 \%$ in patients with primary open-angle glaucoma or ocular hypertension. Clin Ophthalmol. 2012;6:739-746.

11. Leal BC, Medeiros FA, Medeiros FW, Santo RM, Susanna R Jr. Conjunctival hyperemia associated with bimatoprost use a histopathologic study. Am J Ophthalmol. 2004;138:310-313.
12. Chen J, Dinh T, Woodward DF, et al. Bimatoprost: mechanism of ocular surface hyperemia associated with topical therapy. Cardiovasc Drug Rev. 2005;23:231-246.

13. Astin M, Stjernschantz J, Selen G. Role of nitric oxide in PGF2 alphainduced ocular hyperemia. Exp Eye Res. 1994;59:401-407.

14. Patel SC, Spaeth GL. Compliance in patients prescribed eyedrops for glaucoma. Ophthalmic Surg. 1995;26:233-236.
Clinical Ophthalmology

\section{Publish your work in this journal}

Clinical Ophthalmology is an international, peer-reviewed journal covering all subspecialties within ophthalmology. Key topics include: Optometry; Visual science; Pharmacology and drug therapy in eye diseases; Basic Sciences; Primary and Secondary eye care; Patien Safety and Quality of Care Improvements. This journal is indexed on

Submit your manuscript here: http://www.dovepress.com/clinical-ophthalmology-journal

\section{Dovepress}

PubMed Central and CAS, and is the official journal of The Society of Clinical Ophthalmology (SCO). The manuscript management system is completely online and includes a very quick and fair peer-review system, which is all easy to use. Visit http://www.dovepress.com/ testimonials.php to read real quotes from published authors. 